\title{
Oral health-related quality of life in patients with heart failure and left ventricular assist devices-results of a cross-sectional study
}

\author{
Gerhard Schmalz ${ }^{1} \cdot$ Christian Binner $^{2} \cdot$ Mirjam Eisner $^{1}$ - Justus Wagner ${ }^{1} \cdot$ Josephine Rast $^{1} \cdot$ Tanja Kottmann $^{3}$. \\ Rainer Haak ${ }^{1} \cdot$ Sven Lehmann ${ }^{2} \cdot$ Michael A. Borger $^{2} \cdot$ Jens Garbade $^{2} \cdot$ Dirk Ziebolz $^{1}$ (D)
}

Received: 4 November 2020 / Accepted: 16 March 2021 / Published online: 22 March 2021

(C) The Author(s) 2021

\begin{abstract}
Objectives The aim of this cross-sectional study was to compare oral health-related quality of life (OHRQoL) of patients with left ventricular assist device (LVAD) and heart failure (HF).

Material and methods Seventy-four patients with LVAD were recruited from University Department for Cardiac Surgery, Leipzig Heart Center, Germany. A group of 72 patients with HF was composed by matching (age, gender, smoking). The German short form of oral health impact profile (OHIP G14) was applied. Health-related quality of life (HRQoL) was measured by short form 36 survey (SF-36). Dental conditions (decayed-, missing- and filled-teeth [DMF-T]), remaining teeth and periodontal findings were assessed. Statistics: $t$-test, Mann-Whitney $U$ test, Kruskal-Wallis test, chi-square or Fisher test, linear regression.

Results Age, gender, smoking, underlying disease, co-morbidities and oral findings were comparable between groups $(p>0.05)$. OHIP G14 sum score was $3.53 \pm 6.82$ (LVAD) and $2.92 \pm 5.35$ (HF; $p=0.70$ ), respectively. The scales SF-36 physical functioning $(p=0.05)$ and SF-36 social functioning $(p<0.01)$ were worse in LVAD. In the LVAD group, the DMF-T and remaining teeth negatively correlated with OHIP G14 sum score $(p<0.01)$. In HF patients, positive correlations were found between OHIP G14 and D-T $(p<0.01)$ and remaining teeth $(p=0.04)$. Moreover, DMF-T $(p=0.03)$ and remaining molars/ premolars $(p=0.02)$ were negatively correlated with SF-36 scales in HF.

Conclusions Oral health and OHRQoL was comparable between LVAD and HF; thereby, OHRQoL reflected the clinical oral status. Clinical relevance Dental care, with beginning in early stage of HF, should be fostered to preserve teeth and support quality of life before and after LVAD implantation.
\end{abstract}

Keywords Dental care $\cdot$ Left ventricular assist device $\cdot$ Heart failure $\cdot$ Oral health $\cdot$ Oral-related quality of life

\section{Introduction}

For therapy of end-stage heart failure (HF), left ventricular assist devices (LVAD) are becoming increasingly relevant as a definitive substitute for heart transplant or as a bridge to transplantation $[1,2]$. Thereby, LVAD are promising in improving cardiac function, survival and quality of life of the patients $[2,3]$. In contrast, patients treated with LVAD suffer

Dirk Ziebolz

dirk.ziebolz@medizin.uni-leipzig.de

1 Department of Cariology, Endodontology and Periodontology, University Leipzig, Liebigstr. 12, D 04103 Leipzig, Germany

2 University Department for Cardiac Surgery, Leipzig Heart Center, Leipzig, Germany

3 CRO Dr. med. Kottmann GmbH \& Co. KG, Hamm, Germany from a risk of device-related complications as well as complex psychological, emotional and relational complaints, making the real benefit in quality of life still questionable $[2,3]$.

For these patients, oral health issues might be of particular importance. On the one hand, inflammatory diseases of the oral cavity can be related to a risk of infectious complications [4]. It has been reported that DNA of potentially periodontal pathogens, which are related to periodontal diseases, can be detectable in cardiac tissues [5]. This underlines the potential of these bacteria to cause infectious complications and supports the literature suggesting a relationship between periodontitis and coronary heart diseases [6, 7]. Accordingly, standardized protocols for dental care of LVAD patients before and after implantation are recommendable [8]. The only available previous study found a high prevalence of oral diseases, especially periodontal treatment need and a lack in oral behaviour of LVAD patients, without associations to driveline-related complications [9]. 
On the other hand, oral health is an influential factor on health-related quality of life (HRQoL) [10]. In this respect, the oral health-related quality of life (OHRQoL) is the sub aspect of HRQoL, which is primarily related to the perception of oral diseases and conditions [11]. As a patient-reported outcome, the assessment of OHRQoL has developed into a mandatory part of evidence-based dentistry [12]. Up until now, no studies are available, which investigate the associations between oral conditions and OHRQoL as well as HRQoL of patients with LVAD. However, this could be of clinical relevance for different reasons. First, potential explanations for insufficient oral status and dental behaviour of these patients might be derivable; for other at-risk patients, e.g. organ transplantation, oral health was shown to be not related to OHRQoL, indicating that their perception of oral health is not in line with the clinical situation [13-15]. Second, the assessment of potential impacts of oral health on OHRQoL and HRQoL could help to develop individual, patient-centred dental care protocols for patients before and after LVAD implantation. For this, a comparison of patients suffering from HF with and without LVAD is needed.

Accordingly, this current study aimed in the comparison of OHRQoL of patients with LVAD and HF. Furthermore, the relationship between oral health and OHRQoL as well as HRQoL was examined. It was hypothesized that both groups show a comparable OHRQoL that is not affected by oral conditions.

\section{Methods}

This current study was designed as a cross-sectional examination to compare the OHRQoL and HRQoL of patients with LVAD and patients suffering from HF. The study has been reviewed and approved by the ethics committee of the Medical Faculty of University of Leipzig (No: 414/16-ek). All patients were informed verbally and in writing and provided their written informed consent.

\section{Patients}

Patients from the University Department for Cardiac Surgery, Leipzig Heart Center, Leipzig, Germany, were included within their routine follow-up appointment between May 2017 and December 2018. The following inclusion criteria were formed for the LVAD group:

- Age of at least 18 years

- Treatment with LVAD, irrespective of time since implantation

Furthermore, the following exclusion criteria did exist:
- Impossibility to undergo full clinical examination due to worse general health status

- Auto-immune diseases (e.g. rheumatoid arthritis)

- Infectious diseases (hepatitis A, B, C, tuberculosis, HIV)

- Pregnancy

Patients, who met these in- and exclusion criteria, were asked for their voluntary participation and were allocated for oral examination, if informed consent was given. Several general and clinical cardiological data, including smoking habits (self-reported as follows: smoker: currently smoking, non-smoker: no smoking at the time of examination), body mass index (BMI, assessed based on the body weight and height at the time point of examination), ejection fraction, underlying heart diseases and co-morbidities, were extracted from the patients' records. For comparison, a control group of patients suffering from HF from the University Department for Cardiac Surgery, Leipzig Heart Center, Leipzig, Germany, was composed, according to age, gender and smoking habits (matching) of the LVAD group. The exclusion criteria were the same as for the LVAD group.

\section{Questionnaires}

\section{Oral health impact profile (OHIP G14)}

For the assessment of OHRQoL, the short form of oral health impact profile in German language (OHIPG G14) was used [16-18]. This questionnaire included 14 functional and psychosocial impacts that participants have experienced in the previous month related to their teeth, mouth or dentures. For each question, five answering possibilities, i.e. very often = "4", fairly often = "3", occasionally $=$ " 2 ", hardly ever $=$ " 1 " and never $=$ " 0 ", were available. Therefore, a sum score between " 0 ”" (all questions answered with "never") and "56" (all questions answered with "very often") was achievable. Following the principle of minimal important difference [19], differences in OHIP G14 sum score of at least 2 points were interpreted as clinically relevant. Beside of the OHIP G14 sum score, the two major dimensions "oral function" and "psychosocial impact" were analysed [20].

\section{Short form-36 health survey (SF-36)}

For the assessment of HRQoL, the short form-36 survey (SF36) was applied [21]. This questionnaire included a total of 36 items, which can be summarized into the following different scales: physical functioning, role functioning/physical, general health, energy/fatigue, pain, social functioning, emotional well-being and mental well-being. Based on these scales two higher-ordered sum scores, i.e. the physical component summary (PCS) and mental component summary (MCS) measure were determined for further analysis. Data from the scales are presented as raw values (0-100), whereby higher values represent better HRQoL. 


\section{Oral examination}

Two experienced and calibrated dentists (kappa $>0.8$ ) performed the oral examinations at the University Department for Cardiac Surgery, Leipzig Heart Center, Leipzig, Germany, under standardized conditions. An antibiotic prophylaxis ( $2 \mathrm{~g}$ amoxicillin or $600 \mathrm{mg}$ clindamycine) according to the recent guidelines was performed for patients with LVAD prior to clinical oral examination [22].

Within a dental examination, the decayed-(D-T), missing(M-T) and filled-teeth (F-T) index (DMF-T) was assessed visually with mirror and probe in accordance to WHO [23]. Furthermore, the number of remaining teeth (total number of all teeth in the oral cavity), remaining front teeth and remaining molars/premolars was recorded. Within a periodontal examination, periodontal probing depth (PPD) and clinical attachment loss (CAL) was measured with a periodontal probe (PCP 15, Hu-Friedy, Chicago, IL, USA). Thereby, a number of teeth with $\mathrm{PPD} \geq 5 \mathrm{~mm}$ and $\mathrm{CAL} \geq 5 \mathrm{~mm}$ were recorded, respectively.

\section{Statistical analysis}

The statistical analysis was performed with SPSS for Windows, version 24.0 (SPSS Inc., USA). The metric variables were tested for their normal-distribution with Kolmogorov-Smirnov test. The analysis of SF-36 was executed with official analysis software (Hogrefe $\mathrm{GmbH} \& \mathrm{Co}$. KG, Goettingen, Germany). Comparing two independent, normal distributed samples, $t$-test was applied. In case of homogeneity (Levene test), Student's $t$-test was used. Non-normal distributed samples were analysed with Mann-Whitney $U$ test. In comparison of more than two independent, non-normal distributed samples, Kruskal-Wallis test was performed. Categorical data were analysed using chi-square or Fisher test, respectively. For multivariate analysis, a linear regression was conducted. For all applied analyses, a two-sided significance testing was used, whereby the significance level has been set at $p<0.05$.

\section{Results}

\section{Patients}

A total of 74 patients with LVAD and 72 individuals suffering from HF were included. The mean age, gender distribution and smoking habits were comparable between the two groups $(p>0.05)$. The average time since LVAD was $40.72 \pm 22.52$ months. The ejection fraction of LVAD patients was significantly lower than in HF patients $(p<0.01$; Table 1$)$.

\section{Oral examination}

Dental parameters (D-T, DMF-T) and periodontal findings (number of teeth with PPD and/or CAL $\geq 5 \mathrm{~mm}$ ) were comparable between groups $(p>0.05)$. The number of remaining teeth $(18.82 \pm 9.67$ vs. $16.53 \pm 8.75 ; p=0.06)$ and the number
Table 1 Patient characteristics, significance level: $p<0.05$

\begin{tabular}{|c|c|c|c|c|}
\hline & & $\operatorname{LVAD}(n=74)$ & $\mathrm{HF}(n=72)$ & $p$ value \\
\hline \multicolumn{2}{|l|}{ Gender (male in $\%[n]$ ) } & $89.2 \%[66]$ & $88.9 \%[64]$ & 0.99 \\
\hline \multicolumn{2}{|l|}{ Age in years $(\mathrm{mv} \pm \mathrm{sd})$} & $58.20 \pm 9.37$ & $58.20 \pm 8.94$ & 0.64 \\
\hline \multicolumn{2}{|c|}{ Time since LVAD in months $(\mathrm{mv} \pm \mathrm{sd})$} & $40.72 \pm 22.52$ & - & - \\
\hline \multicolumn{2}{|l|}{ Body mass index (BMI, $\mathrm{mv} \pm \mathrm{sd})$} & $28.95 \pm 4.31$ & $28.38 \pm 4.95$ & 0.43 \\
\hline Smoking habits $\%[\mathrm{n}]$ & $\begin{array}{l}\text { Non-smoker } \\
\text { Smoker }\end{array}$ & $\begin{array}{l}91.9 \%[68] \\
8.1 \%[6]\end{array}$ & $\begin{array}{l}91.7 \%[66] \\
8.3 \%[6]\end{array}$ & 0.99 \\
\hline Ejection fraction $(\mathrm{mv} \pm \mathrm{sd})$ & & $22.97 \pm 6.13$ & $27.97 \pm 9.34$ & $<0.01$ \\
\hline \multirow[t]{2}{*}{ Underlying heart disease $\%[n]$} & $\begin{array}{l}\mathrm{dcm} \\
\mathrm{icm}\end{array}$ & $\begin{array}{l}48.6 \%[36] \\
48.6 \%[36]\end{array}$ & $\begin{array}{l}54.2 \%[39] \\
37.5 \%[27]\end{array}$ & \multirow[t]{2}{*}{0.19} \\
\hline & Others & $2.7 \%[2]$ & $8.3 \%[6]$ & \\
\hline \multirow[t]{3}{*}{ Co-morbidities $\%[n]$} & Hypertension & $70.3 \%[52]$ & $77.8 \%[56]$ & 0.35 \\
\hline & Diabetes mellitus & $45.9 \%[34]$ & $38.9 \%[28]$ & 0.41 \\
\hline & Renal insufficiency & $51.4 \%[38]$ & $47.2 \%[34]$ & 0.62 \\
\hline \multirow[t]{3}{*}{ NYHA-classification } & $\begin{array}{l}\text { I } \\
\text { II }\end{array}$ & \multirow[t]{3}{*}{-} & $\begin{array}{l}8.3 \%[6] \\
55.6 \%[40]\end{array}$ & \multirow[t]{3}{*}{-} \\
\hline & III & & $33.3 \%[24]$ & \\
\hline & IV & & $2.8 \%[2]$ & \\
\hline
\end{tabular}

Significant results $(p<0.05)$ are highlighted in bold

$L V A D$ left ventricular assist device, $H F$ heart failure, $m v$ mean value, $s d$ standard deviation, $d c m$, dilatative cardiomyopathy, $\mathrm{icm}$ ischemic cardiomyopathy 
of remaining molars/premolars ( $9.72 \pm 5.56$ vs. $8.00 \pm 5.41 ; p$ $=0.06)$ trended to be higher in LVAD patients (Table 2).

\section{OHIP G14 values}

The OHIP G14 sum score was comparable between both groups, showing mean values of $3.5 \pm 6.8$ (LVAD) and 2.9 \pm 5.4 (HF; $p=0.70$ ). Moreover, the OHIP G14 dimensions psychosocial impact $(p=0.87)$ and oral function $(p=$ 0.88 ) were comparable between LVAD and HF patients (Table 2). As presented in Table 3, none of the 14 questions from OHIP G14 showed a significant difference between the two groups (Table 3).

\section{SF-36 values}

Two scales of SF-36 were found to be significantly different between the two groups. The scale SF-36 physical functioning was significantly worse in LVAD compared to HF patients $(42.1 \pm 24.5$ vs. $50.0 \pm 26.6 ; p=0.05)$. Moreover, the scale SF-36 social functioning was worse in the LVAD group (68.6 \pm 27.2 vs. $81.4 \pm 23.4 ; p<0.01)$. Further SF-36 findings are given in Table 4.

\section{Correlations between OHIP G14 as well as HRQoL and oral health}

In the LVAD group, the DMF-T $(\beta:-1.05$, CI95: -1.57 to $0.30)$, number of remaining teeth $(\beta:-1.12$, CI95: -2.54 to $0.56)$ and number of remaining molars/premolars $(\beta$ : -1.26 , CI95: -2.57 to -0.47$)$ negatively correlated significantly with OHIP G14 sum score ( $p<0.01$; Table 5$)$. In HF patients, positive correlations were found between OHIP G14 and D-T $(\beta: 0.60$, CI95: $1.45-2.68 ; p<0.01)$ as well as the number of remaining teeth $(\beta: 0.19$, CI95: $-0.01-0.23 ; p=0.04)$. Moreover, DMF-T ( $\beta$ : -0.45 , CI95: -1.25 to $-0.06 ; p=$ $0.03)$ and number of remaining molars/premolars $(\beta$ : -0.49 , C195: -1.73 to $-0.16 ; p=0.02$ ) were negatively correlated with PCS of SF-36 in HF group. Additionally, a negative correlation between D-T $(\beta$ : -0.36 , CI95: -3.46 to -0.82 ; $p<0.01)$ and MCS of SF-36 was detected in HF patients (Table 6).

\section{Discussion}

\section{Summary of the main results}

Both, oral health and OHRQoL were comparable between LVAD and HF patients. Two scales in SF-36 were worse in LVAD patients. Within the LVAD group, oral conditions were correlated to OHRQoL, while in the HF group correlations were found for both, OHRQoL and HRQoL.

\section{Comparison with published data}

This is the first study, which examined the relationship between oral health and OHRQoL as well as HRQoL in patients with LVAD in comparison to HF patients. Therefore, the comparability to available literature is limited. If data for German general population are considered, a DMF-T of 17.7, a D-T of 0.5 and on average 11.1 missing teeth (means about 17 remaining teeth based on 28 teeth in full dentition) has been reported in fifth German oral health study (DMS V) for patients 65-74 years of age [24]. This appears almost comparable to the current study's findings for LVAD and HF groups, indicating comparable oral conditions with generally healthy individuals in Germany. Moreover, both groups
Table 2 Results of the dental findings and OHIP G14 scores between groups, significance level: $p<0.05$

\begin{tabular}{llll}
\hline & LVAD $(n=74)$ & HF $(n=72)$ & $p$ value \\
\hline DMF-T $(\mathrm{mv} \pm \mathrm{sd})$ & $17.45 \pm 7.66$ & $18.21 \pm 7.11$ & 0.57 \\
$\mathrm{D}-\mathrm{T}(\mathrm{mv} \pm \mathrm{sd})$ & $0.36 \pm 1.33$ & $0.50 \pm 1.56$ & 0.25 \\
Remaining teeth $(\mathrm{mv} \pm \mathrm{sd})$ & $18.82 \pm 9.67$ & $16.53 \pm 8.75$ & 0.06 \\
Remaining front teeth $(\mathrm{mv} \pm \mathrm{sd})$ & $9.11 \pm 4.39$ & $8.63 \pm 3.90$ & 0.13 \\
Remaining molars/premolars $(\mathrm{mv} \pm \mathrm{sd})$ & $9.72 \pm 5.56$ & $8.00 \pm 5.41$ & 0.06 \\
Number of teeth CAL $\geq 5 \mathrm{~mm}(\mathrm{mv} \pm \mathrm{sd})$ & $4.78 \pm 5.36$ & $5.07 \pm 4.96$ & 0.43 \\
Number of teeth PPD $\geq 5 \mathrm{~mm}(\mathrm{mv} \pm \mathrm{sd})$ & $6.72 \pm 6.77$ & $5.31 \pm 5.42$ & 0.35 \\
OHIP G14 sum $(\mathrm{mv} \pm \mathrm{sd})$ & $3.5 \pm 6.8[0,0-5.0]$ & $2.9 \pm 5.4[0,0-4.0]$ & 0.70 \\
Psychosocial impact sum $(\mathrm{mv} \pm \mathrm{sd})$ & $1.9 \pm 4.3[0,0-1.0]$ & $1.4 \pm 3.7[0,0-2.0]$ & 0.87 \\
Oral function sum $(\mathrm{mv} \pm \mathrm{sd})$ & $1.1 \pm 2.2[0,0-1.0]$ & $1.0 \pm 1.8[0,0-1.0]$ & 0.88 \\
\hline
\end{tabular}

OHIP values are given as mean value \pm standard deviation [median; 25 th -75 th percentile]; significant results $(p<$ 0.05 ) are highlighted in bold

$L V A D$ left ventricular assist device, $H F$ heart failure, $m v$ mean value, $s d$ standard deviation, $D M F-T$ decayed-, missing- and filled-teeth index, $O H I P$ oral health impact profile 
Table 3 results of the OHIP-G14 questionnaire, significance level: $p<0.05$

\begin{tabular}{|c|c|c|c|c|c|c|c|}
\hline \multirow{2}{*}{$\begin{array}{l}\text { Question } \\
{[n]}\end{array}$} & \multirow[t]{2}{*}{ Group } & \multicolumn{5}{|l|}{ Point score } & \multirow[t]{2}{*}{$p$ value } \\
\hline & & $\begin{array}{l}\text { Never } \\
\text { (rating 0) }\end{array}$ & $\begin{array}{l}\text { Rarely } \\
\text { (rating 1) }\end{array}$ & $\begin{array}{l}\text { Sometimes } \\
\text { (rating 2) }\end{array}$ & $\begin{array}{l}\text { Often } \\
\text { (rating 3) }\end{array}$ & $\begin{array}{l}\text { Very often } \\
\text { (rating 4) }\end{array}$ & \\
\hline Trouble pronouncing & $\begin{array}{l}\text { LVAD } \\
\text { HF }\end{array}$ & $\begin{array}{l}60 \\
60\end{array}$ & $\begin{array}{l}9 \\
8\end{array}$ & $\begin{array}{l}5 \\
2\end{array}$ & $\begin{array}{l}0 \\
2\end{array}$ & $\begin{array}{l}0 \\
0\end{array}$ & 0.35 \\
\hline Taste worsened & $\begin{array}{l}\text { LVAD } \\
\text { HF }\end{array}$ & $\begin{array}{l}64 \\
60\end{array}$ & $\begin{array}{l}6 \\
8\end{array}$ & $\begin{array}{l}3 \\
3\end{array}$ & $\begin{array}{l}1 \\
1\end{array}$ & $\begin{array}{l}0 \\
0\end{array}$ & 0.91 \\
\hline Life less satisfying & $\begin{array}{l}\text { LVAD } \\
\text { HF }\end{array}$ & $\begin{array}{l}61 \\
55\end{array}$ & $\begin{array}{l}8 \\
12\end{array}$ & $\begin{array}{l}3 \\
2\end{array}$ & $\begin{array}{l}1 \\
2\end{array}$ & $\begin{array}{l}1 \\
1\end{array}$ & 0.81 \\
\hline Difficult to relax & $\begin{array}{l}\text { LVAD } \\
\text { HF }\end{array}$ & $\begin{array}{l}63 \\
61\end{array}$ & $\begin{array}{l}6 \\
7\end{array}$ & $\begin{array}{l}2 \\
2\end{array}$ & $\begin{array}{l}3 \\
1\end{array}$ & $\begin{array}{l}0 \\
1\end{array}$ & 0.72 \\
\hline Feeling of tension & $\begin{array}{l}\text { LVAD } \\
\text { HF }\end{array}$ & $\begin{array}{l}61 \\
66\end{array}$ & $\begin{array}{l}10 \\
3\end{array}$ & $\begin{array}{l}1 \\
2\end{array}$ & $\begin{array}{l}2 \\
0\end{array}$ & $\begin{array}{l}0 \\
1\end{array}$ & 0.12 \\
\hline Interrupting meals & $\begin{array}{l}\text { LVAD } \\
\text { HF }\end{array}$ & $\begin{array}{l}63 \\
66\end{array}$ & $\begin{array}{l}8 \\
6\end{array}$ & $\begin{array}{l}3 \\
0\end{array}$ & $\begin{array}{l}0 \\
0\end{array}$ & $\begin{array}{l}0 \\
0\end{array}$ & 0.19 \\
\hline Uncomfortable to eat & $\begin{array}{l}\text { LVAD } \\
\text { HF }\end{array}$ & $\begin{array}{l}64 \\
60\end{array}$ & $\begin{array}{l}6 \\
8\end{array}$ & $\begin{array}{l}3 \\
2\end{array}$ & $\begin{array}{l}1 \\
1\end{array}$ & $\begin{array}{l}0 \\
0\end{array}$ & 0.32 \\
\hline Short tempered & $\begin{array}{l}\text { LVAD } \\
\text { HF }\end{array}$ & $\begin{array}{l}64 \\
64\end{array}$ & $\begin{array}{l}7 \\
6\end{array}$ & $\begin{array}{l}2 \\
1\end{array}$ & $\begin{array}{l}1 \\
0\end{array}$ & $\begin{array}{l}0 \\
1\end{array}$ & 0.67 \\
\hline Difficulty performing jobs & $\begin{array}{l}\text { LVAD } \\
\text { HF }\end{array}$ & $\begin{array}{l}60 \\
66\end{array}$ & $\begin{array}{l}8 \\
1\end{array}$ & $\begin{array}{l}3 \\
4\end{array}$ & $\begin{array}{l}2 \\
0\end{array}$ & $\begin{array}{l}1 \\
1\end{array}$ & 0.10 \\
\hline Unable to function & $\begin{array}{l}\text { LVAD } \\
\text { HF }\end{array}$ & $\begin{array}{l}63 \\
68\end{array}$ & $\begin{array}{l}7 \\
2\end{array}$ & $\begin{array}{l}0 \\
1\end{array}$ & $\begin{array}{l}3 \\
0\end{array}$ & $\begin{array}{l}1 \\
1\end{array}$ & 0.14 \\
\hline Embarrassed & $\begin{array}{l}\text { LVAD } \\
\text { HF }\end{array}$ & $\begin{array}{l}61 \\
64\end{array}$ & $\begin{array}{l}8 \\
5\end{array}$ & $\begin{array}{l}3 \\
2\end{array}$ & $\begin{array}{l}1 \\
0\end{array}$ & $\begin{array}{l}1 \\
1\end{array}$ & 0.75 \\
\hline Diet unsatisfactory & $\begin{array}{l}\text { LVAD } \\
\text { HF }\end{array}$ & $\begin{array}{l}64 \\
63\end{array}$ & $\begin{array}{l}7 \\
7\end{array}$ & $\begin{array}{l}1 \\
1\end{array}$ & $\begin{array}{l}2 \\
0\end{array}$ & $\begin{array}{l}0 \\
1\end{array}$ & 0.56 \\
\hline Oral pain & $\begin{array}{l}\text { LVAD } \\
\text { HF }\end{array}$ & $\begin{array}{l}59 \\
57\end{array}$ & $\begin{array}{l}7 \\
11\end{array}$ & $\begin{array}{l}8 \\
4\end{array}$ & $\begin{array}{l}0 \\
0\end{array}$ & $\begin{array}{l}0 \\
0\end{array}$ & 0.33 \\
\hline Sense of uncertainty & $\begin{array}{l}\text { LVAD } \\
\text { HF }\end{array}$ & $\begin{array}{l}61 \\
64\end{array}$ & $\begin{array}{l}6 \\
5\end{array}$ & $\begin{array}{l}6 \\
2\end{array}$ & $\begin{array}{l}1 \\
0\end{array}$ & $\begin{array}{l}0 \\
1\end{array}$ & 0.75 \\
\hline
\end{tabular}

Significant results $(p<0.05)$ are highlighted in bold $L V A D$ left ventricular assist device, $H F$ heart failure

Table 4 SF-36 between groups, significance level: $p<0.05$

\begin{tabular}{llll}
\hline parameter & LVAD $(n=74)$ & HF $(n=72)$ & $p$ value \\
\hline SF-36 physical functioning $(\mathrm{mv} \pm \mathrm{sd})$ & $42.1 \pm 24.5$ & $50.0 \pm 26.6$ & $\mathbf{0 . 0 5}$ \\
SF-36 role functioning/physical $(\mathrm{mv} \pm \mathrm{sd})$ & $30.1 \pm 42.0$ & $27.2 \pm 42.2$ & 0.26 \\
SF-36 general health $(\mathrm{mv} \pm \mathrm{sd})$ & $42.5 \pm 17.4$ & $45.4 \pm 17.7$ & 0.29 \\
SF-36 energy/fatigue $(\mathrm{mv} \pm \mathrm{sd})$ & $46.2 \pm 22.1$ & $47.5 \pm 18.9$ & 0.62 \\
SF-36 pain $(\mathrm{mv} \pm \mathrm{sd})$ & $75.8 \pm 28.8$ & $75.0 \pm 26.7$ & 0.61 \\
SF-36 social functioning $(\mathrm{mv} \pm \mathrm{sd})$ & $68.6 \pm 27.2$ & $81.4 \pm 23.4$ & $<\mathbf{0 . 0 1}$ \\
SF-36 emotional well-being $(\mathrm{mv} \pm \mathrm{sd})$ & $63.1 \pm 46.0$ & $70.0 \pm 43.0$ & 0.40 \\
SF-36 mental well-being $(\mathrm{mv} \pm \mathrm{sd})$ & $68.7 \pm 21.2$ & $69.0 \pm 17.6$ & 0.83 \\
Physical compound summary $(\mathrm{mv} \pm \mathrm{sd})$ & $34.9 \pm 8.8$ & $36.9 \pm 10.3$ & 0.27 \\
Mental compound summary $(\mathrm{mv} \pm \mathrm{sd})$ & $48.8 \pm 12.6$ & $50.4 \pm 9.3$ & 0.67 \\
\hline
\end{tabular}

Significant results $(\mathrm{p}<0.05)$ are highlighted in bold

$L V A D$ left ventricular assist device, $H F$ heart failure, $m v$ mean value, $s d$ standard deviation, $S F-36$ short form 36 survey 
Table 5 Regression analysis of predictors of OHIP G14 sum score, as well as physical and mental compound summary of SF-36 in patients with LVAD

\begin{tabular}{|c|c|c|c|c|c|c|}
\hline & \multicolumn{2}{|l|}{ OHIP G14 } & \multicolumn{2}{|l|}{ PCS } & \multicolumn{2}{|l|}{ MCS } \\
\hline & $\beta\left[\mathrm{CI}_{95}\right]$ & $p$ value & $\beta\left[\mathrm{CI}_{95}\right]$ & $p$ value & $\beta\left[\mathrm{CI}_{95}\right]$ & $p$ value \\
\hline $\mathrm{D}-\mathrm{T}$ & $\begin{array}{l}0.04 \\
{[-1.25-1.53]}\end{array}$ & 0.76 & $\begin{array}{l}0.12 \\
{[-0.94-2.54]}\end{array}$ & 0.36 & $\begin{array}{l}0.04 \\
{[-2.08-2.80]}\end{array}$ & 0.77 \\
\hline DMF-T & $\begin{array}{l}-1.05 \\
{[-1.57 \text { to }-0.30]}\end{array}$ & $<0.01$ & $\begin{array}{l}0.29 \\
{[-0.66-1.32]}\end{array}$ & 0.51 & $\begin{array}{l}0.54 \\
{[-0.49-2.28]}\end{array}$ & 0.20 \\
\hline Remaining teeth & $\begin{array}{l}-1.12 \\
{[-2.54 \text { to }-0.56]}\end{array}$ & $<0.01$ & $\begin{array}{l}0.27 \\
{[-0.98-1.88]}\end{array}$ & 0.35 & $\begin{array}{l}0.67 \\
{[-0.62-3.24]}\end{array}$ & 0.26 \\
\hline Remaining molars/premolars & $\begin{array}{l}-1.26 \\
{[-2.57 \text { to }-0.47]}\end{array}$ & $<0.01$ & $\begin{array}{l}0.38 \\
{[-1.05-2.24]}\end{array}$ & 0.47 & $\begin{array}{l}0.78 \\
{[-0.56-4.06]}\end{array}$ & 0.14 \\
\hline
\end{tabular}

Significant results $(\mathrm{p}<0.05)$ are highlighted in bold

LVAD left ventricular assist device, $O H I P$ oral health impact profile, $S F-36$ short form 36 survey, $D M F-T$ decayed-, missing- and filled-teeth index

showed on average more than five teeth with PPD $\geq 5 \mathrm{~mm}$, which argues for a remarkable periodontal treatment need. This is also in line with DMS V for general population [24]. A Chinese cross-sectional study found comparable results, but only examined patients after heart transplantation [25]. In context of oral conditions, a lower number of remaining teeth in LVAD would have been expectable. Recent concepts of dental management prior to LVAD implantation is primarily based on surgical procedures, especially the removal of potential infectious foci by tooth extraction $[8,26,27]$. Remaining teeth were negatively correlated to OHRQoL measurement in the LVAD group. This means that a higher number of remaining teeth is related to lower OHIP G14 sum score, what reflects higher OHRQoL. Therefore, an increased number of remaining teeth, especially molars/premolars appears to have a positive effect on OHRQoL of LVAD patients. This is in line with general literature, showing that tooth loss and the number of functional occlusion pairs (especially molars) are a strong influential factor on OHRQoL $[28,29]$. Therefore, dental care protocols for LVAD patients might be more prevention oriented to allow tooth preservation against radical surgical rehabilitation, if possible.

For interpretation of OHRQoL in general, reference values for German population can be consulted. Thereby, values between 0 and 4 points, depending on dentition, can be seen as unaffected OHRQoL [30]. Both, LVAD and HF group are completely within this range. This appears similar to patients after organ transplantation, which also regularly showed an unaffected OHRQoL in comparable studies [13-15]. Accordingly, an unaffected OHRQoL of patients with LVAD and with HF can be concluded from the current study. In contrast to the upper mentioned previous studies on organ transplant recipients [13-15], the examined oral conditions were found to be correlated to OHRQoL in the LVAD as well as HF group. Thereby, the correlation was more strongly in the LVAD group and appears especially relevant regarding remaining teeth.

To interpret the HRQoL of the included individuals, reference values for German patients with heart failure have already been reported [31]. The reference value for PCS is

Table 6 Regression analysis of predictors of OHIP G14 sum score, as well as physical and mental compound summary of SF-36 in patients with HF

\begin{tabular}{|c|c|c|c|c|c|c|}
\hline & \multicolumn{2}{|l|}{ OHIP G14 } & \multicolumn{2}{|l|}{ PCS } & \multicolumn{2}{|l|}{ MCS } \\
\hline & $\beta\left[\mathrm{CI}_{95}\right]$ & $p$ value & $\beta\left[\mathrm{CI}_{95}\right]$ & $p$ value & $\beta\left[\mathrm{CI}_{95}\right]$ & $p$ value \\
\hline $\mathrm{D}-\mathrm{T}$ & $\begin{array}{l}0.60 \\
{[1.45-2.68]}\end{array}$ & $<0.01$ & $\begin{array}{l}-0.06 \\
{[-3.57-2.84]}\end{array}$ & 0.82 & $\begin{array}{l}-0.36 \\
{[-3.46 \text { to }-0.82]}\end{array}$ & $<0.01$ \\
\hline DMF-T & $\begin{array}{l}0.79 \\
{[-1.18-1.30]}\end{array}$ & 0.92 & $\begin{array}{l}-0.45 \\
{[-1.25 \text { to }-0.06]}\end{array}$ & 0.03 & $\begin{array}{l}-0.46 \\
{[-3.24-2.02]}\end{array}$ & 0.65 \\
\hline Remaining teeth & $\begin{array}{l}0.19 \\
{[-0.01-0.23]}\end{array}$ & 0.04 & $\begin{array}{l}-0.57 \\
{[-3.35-1.98]}\end{array}$ & 0.61 & $\begin{array}{l}-0.35 \\
{[-2.84-2.07]}\end{array}$ & 0.76 \\
\hline Remaining molars/premolars & $\begin{array}{l}-0.14 \\
{[-0.89-0.61]}\end{array}$ & 0.71 & $\begin{array}{l}-0.49 \\
{[-1.73 \text { to }-0.16]}\end{array}$ & 0.02 & $\begin{array}{l}-0.18 \\
{[-1.93-1.32]}\end{array}$ & 0.71 \\
\hline
\end{tabular}

Significant results $(p<0.05)$ are highlighted in bold

$H F$ heart failure, $O H I P$ oral health impact profile, $S F-36$ short form 36 survey, $D M F-T$ decayed-, missing- and filled-teeth index 
$42.8 \pm 9.331$, what is slightly higher than in the two groups within the current study. The MCS value of German patients with HF was reported to be $46.6 \pm 10.831$, what is almost comparable to the current study. Interestingly, LVAD patients in the current study showed worse results in two scales of SF36 , i.e. physical and social functioning. It has been reported that LVAD implantation would lead to improved quality of life [2, 3, 32]. However, a recent systematic review stated that only some aspects of quality of life would be improved after LVAD implantation [33]. The remaining functional and emotional limitations might lead to an impairment of some HRQoL domains, as confirmed in the current study. Thereby it needs to be mentioned, that the HF group was quite heterogeneous regarding the severity of HF (NYHA class). Regardless, oral conditions were found to be negatively correlated with HRQoL in the HF group, indicating that a higher DMF-T and more remaining molars/premolars lead to worse HRQoL. This is somewhat surprising regarding the number of remaining molars/premolars, but might indicate that these remaining teeth cause more complaints if they are still in the oral cavity (e.g. periodontal inflammation, loosening or hypersensitivity). The relation between HRQoL and oral health was not found in the LVAD group. This might indicate that LVAD patients might be primarily affected by LVAD therapy and related complaints in their quality of life. Accordingly, oral conditions only affect OHRQoL in these patients, but not HRQoL. The HF patients, especially if HF is not very severe, perceive affection in both, OHRQoL and HRQoL. However, this remains only speculative and needs to be further evaluated in future studies.

Altogether, the results of the current study indicate several points of clinical relevance. Because of the strong correlation between remaining teeth and OHRQoL in LVAD patients, prevention oriented dental care might be preferable. Furthermore, oral conditions are a predictor of several scales of OHRQoL and HRQoL of patients with HF. In combination with the information that oral diseases, especially periodontitis can be related to morbidity and mortality in patients with severe heart diseases $[6,7]$, an early dental rehabilitation and consequent dental care appears recommendable. Therefore, special dental care protocols, as demanded in literature [8] should not start immediately before LVAD, but in early stage of HF. A subsequent, individual preventive dental care would stabilize the oral conditions and might avoid the necessity of radical surgical rehabilitation prior to LVAD (and/or heart transplantation). Nevertheless, this needs further evaluation in prospective studies in future. In general, the self-reported oral health $(\mathrm{OHRQ} \mathrm{L})$ correlated with objective or clinically assessed oral health status in the current study. Therefore, in this patient population, the self-assessed oral health appear to reflect the oral health status. Already the screening of the
OHRQoL with the use of questionnaires, for example, in a cardiology clinic, could detect patients who need to be preferably referred to a dentist. This might be a further approach for improving dental care in these patients.

\section{Strengths and limitations}

This is the first study comparing OHRQoL and HRQoL with regard to oral conditions in patients with LVAD and HF. The applied methods are standardized and valid. The groups were matched and comparable regarding underlying diseases and co-morbidities. Several limitations need to be addressed. Considering the fact that patients with a severe general disease were included, more than 70 patients in each group appear an appropriate sample size; however, no sample size calculation was performed, making the statistical robustness of the findings somewhat questionable. Especially regarding regression analysis, conclusions based on these results must be interpreted with caution. Moreover, the current study was a monocentric, cross-sectional study. Thus, the findings are not representative for Germany and causative conclusions cannot be drawn by this study design. The values of both groups were interpreted with regard to national reference values; for more strong conclusions, a healthy control group might have been recruited, but would not provide relevant additional information for the primary study question. In summary, longitudinal studies with a large sample size should be striven in the future.

\section{Conclusion}

Oral conditions and OHRQoL is comparable between LVAD and HF patients. LVAD patients showed slightly worse HRQoL. Prevention oriented dental care, with beginning in early stage of HF might be recommendable to avoid the necessity of radical surgical rehabilitation before LVAD and should be fostered to preserve teeth and support quality of life in these patients.

Acknowledgements We would like to thank the medical team of the University Department for Cardiac Surgery, Leipzig Heart Center, Leipzig, Germany for organizing the patient management.

Author contributions Conceptualization: Dirk Ziebolz, Christian Binner, Jens Garbade and Gerhard Schmalz; Data curation: Christian Binner, Josephine Rast, Mirjam Eisner and Justus Wagner; Formal analysis: Tanja Kottmann; Methodology: Dirk Ziebolz and Christian Binner; Project administration: Dirk Ziebolz, Christian Binner, Sven Lehmann, Jens Garbade and Gerhard Schmalz; Supervision: Dirk Ziebolz, Rainer Haak, Michael A. Borger and Jens Garbade; Writing - original draft, Gerhard Schmalz; Writing - review \& editing, Dirk Ziebolz, Christian Binner, Josephine Rast, Mirjam Eisner, Justus Wagner, Tanja Kottmann, Rainer Haak, Michael A. Borger, Sven Lehmann, and Jens Garbade. 
Funding Open Access funding enabled and organized by Projekt DEAL. The authors declare no grants or financial support.

\section{Declarations}

Ethics approval All procedures performed in the current study were in accordance with the ethical standards of the institutional ethics committee (No: 414/16-ek) and with the 1964 Helsinki declaration and its later amendments or comparable ethical standards.

Consent to participate Informed consent was obtained from all individual participants included in the study.

Conflict of interest Gerhard Schmalz declares that he has no conflict of interest. Christian Binner declares that he has no conflict of interest. Mirjam Eisner declares that she has no conflict of interest. Justus Wagner declares that he has no conflict of interest. Josephine Rast declares that she has no conflict of interest. Tanja Kottmann declares that she has no conflict of interest. Rainer Haak declares that he has no conflict of interest. Sven Lehmann declares that he has no conflict of interest. Michael A. Borger declares that he has no conflict of interest. Jens Garbade declares that he has no conflict of interest. Dirk Ziebolz declares that he has no conflict of interest.

Open Access This article is licensed under a Creative Commons Attribution 4.0 International License, which permits use, sharing, adaptation, distribution and reproduction in any medium or format, as long as you give appropriate credit to the original author(s) and the source, provide a link to the Creative Commons licence, and indicate if changes were made. The images or other third party material in this article are included in the article's Creative Commons licence, unless indicated otherwise in a credit line to the material. If material is not included in the article's Creative Commons licence and your intended use is not permitted by statutory regulation or exceeds the permitted use, you will need to obtain permission directly from the copyright holder. To view a copy of this licence, visit http://creativecommons.org/licenses/by/4.0/.

\section{References}

1. Mancini D, Colombo PC (2015) Left ventricular assist devices: a rapidly evolving alternative to transplant. J Am Coll Cardiol 65: 2542-2555

2. Thiha S, Zaidi ARZ, Robert CA, Abbas MK, Malik BH (2019) A rising hope of an artificial heart: left ventricular assisted device outcome, convenience, and quality of life. Cureus 11:e5617

3. Modica M, Ferratini M, Torri A, Oliva F, Martinelli L, De Maria R, Frigerio M (2015) Quality of life and emotional distress early after left ventricular assist device implant: a mixed-method study. Artif Organs 39:220-227

4. Kumar PS (2013) Oral microbiota and systemic disease. Anaerobe 24:90-93

5. Ziebolz D, Jahn C, Pegel J, Semper-Pinnecke E, Mausberg RF, Waldmann-Beushausen R, Schöndube FA, Danner BC (2018) Periodontal bacteria DNA findings in human cardiac tissue - Is there a link of periodontitis to heart valve disease? Int J Cardiol 251:74-79

6. Kebschull M, Demmer RT, Papapanou PN (2010) "Gum bug, leave my heart alone!"-epidemiologic and mechanistic evidence linking periodontal infections and atherosclerosis. J Dent Res 89:879-902

7. Batty GD, Jung KJ, Mok Y, Lee SJ, Back JH, Lee S, Jee SH (2018) Oral health and later coronary heart disease: cohort study of one million people. Eur J Prev Cardiol 25:598-605
8. Javed F, Khan J, Youssef M, Divakar DD, Michelogiannakis D (2020) Dental management of patients with congestive heart failure before and after implantation of ventricular assist devices: linking the missing protocol. Scand Cardiovasc J 54:206-211

9. Garbade J, Rast J, Schmalz G, Eisner M, Wagner J, Kottmann T, Oberbach A, Lehmann S, Haak R, Borger MA, Binner C, Ziebolz D (2020) Oral health and dental behaviour of patients with left ventricular assist device: a cross-sectional study. ESC Heart Fail $7: 1273-1281$

10. Haag DG, Peres KG, Balasubramanian M, Brennan DS (2017) Oral conditions and health-related quality of life: a systematic review. J Dent Res 96:864-874

11. Reissmann DR, John MT, Schierz O, Kriston L, Hinz A (2013) Association between perceived oral and general health. J Dent 41: 581-589

12. Reissmann DR (2020) Methodological considerations when measuring oral health-related quality of life. J Oral Rehabil 2020. https://doi.org/10.1111/joor.12983

13. Schmalz G, Kollmar O, Vasko R, Müller GA, Haak R, Ziebolz D (2016) Oral health-related quality of life in patients on chronic haemodialysis and after kidney transplantation. Oral Dis 22:665672

14. Schmalz G, Wendorff H, Marcinkowski A, Weinreich G, Teschler H, Haak R, Sommerwerck U, Ziebolz D (2018) Oral health related quality of life depending on oral health and specific factors in patients after lung transplantation. Clin Respir J 12:731-737

15. Schmalz G, Eisner M, Binner C, Wagner J, Rast J, Kottmann T, Haak R, Oberbach A, Borger MA, Garbade J, Ziebolz D (2020) Oral health-related quality of life of patients after heart transplantation and those with heart failure is associated with general healthrelated quality of life: a cross-sectional study. Qual Life Res 29: $1621-1630$

16. Slade GD, Spencer AJ (1994) Development and evaluation of the oral health impact profile. Community Dent Health 11:3-11

17. Slade GD (1997) Derivation and validation of a short-form oral health impact profile. Community Dent Oral Epidemiol 25:284 290

18. John MT, Patrick DL, Slade GD (2002) The German version of the oral health impact profile-translation and psychometric properties. Eur J Oral Sci 110:425-433

19. Reissmann DR, Krautz M, Schierz O, John MT (2008) Assessment of clinically significant changes in oral health. German Dent J 63: 668-680

20. John MT, Rener-Sitar K, Baba K, Čelebić A, Larsson P, Szabo G, Norton WE, Reissmann DR (2016) Patterns of impaired oral healthrelated quality of life dimensions. J Oral Rehabil 43:519-527

21. Ware JE, Kosinski M (2005) SF-36 @ physical and mental health summary scales: a manual for users of version 1. 2. Lincoln, QualityMetric Incorporated

22. Wilson W, Taubert KA, Gewitz M, Lockhart PB, Baddour LM, Levison M, Bolger A, Cabell CH, Takahashi M, Baltimore RS, Newburger JW, Strom BL, Tani LY, Gerber M, Bonow RO, Pallasch T, Shulman ST, Rowley AH, Burns JC, Ferrieri P, Gardner T, Goff D, Durack DT, American Heart Association Rheumatic Fever, Endocarditis, and Kawasaki Disease Committee, American Heart Association Council on Cardiovascular Disease in the Young, American Heart Association Council on Clinical Cardiology, American Heart Association Council on Cardiovascular Surgery and Anesthesia, Quality of Care and Outcomes Research Interdisciplinary Working Group (2007) Prevention of infective endocarditis: guidelines from the American Heart Association: a guideline from the American Heart Association Rheumatic Fever, Endocarditis, and Kawasaki Disease Committee, Council on Cardiovascular Disease in the Young, and the Council on Clinical Cardiology, Council on Cardiovascular Surgery and Anesthesia, and the Quality of Care 
and Outcomes Research Interdisciplinary Working Group. Circulation 116:1736-1754

23. WHO (1997) World Health Organization: Oral health surveys, basic methods 4th edition. WHO; Oral Health Unit, Genf

24. Jordan RA, Micheelis W (2016) The Fifth German Oral Health Study (DMS V). Institut der Deutschen Zahnärzte (Hrsg.); (IDZ Materialienreihe Band 35). Deutscher Zahnärzte Verlag DÄV, Köln 2016. [in German]

25. Cao CX, Jia Y, Lv Y, Sun Z (2018) Oral health status of adult heart transplant recipients in China: A cross-sectional study. Medicine (Baltimore) 97:e12508

26. Morimoto Y, Nakatani T, Yokoe C, Kudo C, Hanamoto H, Niwa H (2015) Haemostatic management for oral surgery in patients supported with left ventricular assist device-a preliminary retrospective study. Br J Oral Maxillofac Surg 53:991-995

27. Findler M, Findler M, Rudis E (2011) Dental treatment of a patient with an implanted left ventricular assist device: expanding the frontiers. Oral Surg Oral Med Oral Pathol Oral Radiol Endod 111:e1-e4

28. Tan H, Peres KG, Peres MA (2016) Retention of Teeth and Oral Health-Related Quality of Life. J Dent Res 95:1350-1357

29. Gerritsen AE, Allen PF, Witter DJ, Bronkhorst EM, Creugers NH (2010) Tooth loss and oral health-related quality of life: a systematic review and meta-analysis. Health Qual Life Outcomes 8:126
30. John MT, Micheelis W, Biffar R (2004) Reference values in oral health-related quality of life for the abbreviated version of the oral health impact profile. Swiss Dent J 114:784-791

31. Huber A, Oldridge N, Höfer S (2016) International SF-36 reference values in patients with ischemic heart disease. Qual Life Res 25: 2787-2798

32. Dahrmann B, Sindermann J, Geldmacher T, Heuft G (2017) Lebensqualität und psychisches Befinden von Patienten mit schwerer Herzinsuffizienz mit und ohne apparative Unterstützung der Funktion des linken Ventrikels - eine Querschnittsstudie [Quality of life and mental health of patients with severe heart failure with or without technical support for the left cardiac ventricle - a cross-sectional study]. Z Psychosom Med Psychother 63: 388-404 German

33. Adams EE, Wrightson ML (2018) Quality of life with an LVAD: A misunderstood concept. Heart Lung 47:177-183

Publisher's note Springer Nature remains neutral with regard to jurisdictional claims in published maps and institutional affiliations. 